${ }^{1}$ Северо-Западный государственный медицинский университет

им. И.И. Мечникова

${ }^{2}$ Первый Санкт-

Петербургский медицинский университет

им. акад. И.П. Павлова

${ }^{3}$ Клиника имени Петра Великого,

Северо-Западный

государственный медииинский университет им. И.И. Мечникова

\title{
Системный амилоидоз:
} клинические проявления и диагностика

\author{
Н.В. Бакулина, д.м.н., проф. ${ }^{1}$, А.С. Некрасова, к.м.н. ${ }^{1}$, А.Я. Гудкова, д.м.н., \\ проф. ${ }^{2}$, Э.Л. Латария, к.м.н. ${ }^{3}$, В.В. Гомонова ${ }^{3}$, Д.Б. Цурцумия, к.м.н. ${ }^{1}$
}

Адрес для переписки: Наталья Валерьевна Бакулина, natalya.bakulina@szgmu.ru

Для цитирования: Бакулина Н.В., Некрасова А.С., Гудкова А.Я. и др. Системный амилоидоз: клинические проявления и диагностика // Эффективная фармакотерапия. 2020. Т. 16. № 24. С. 68-76.

DOI 10.33978/2307-3586-2020-16-24-68-76

\section{Данный обзор посвящен современному состоянию проблемы диагностики системного амилоидоза на амбулаторном этапе и в условиях} многопрофильного стационара. В статье обобщены сведения о вариантах клинического течения и представлены актуальные способы верификации данного заболевания. При системном амилоидозе вовлечение в патологический проиесс различных систем и органов, многообразие клинических проявлений и неспеиифичные жалобы больного на ранних стадиях зачастую приводят $\kappa$ несвоевременной постановке правильного диагноза и позднему началу течения, что ухудшает прогноз и создает существенную угрозу для жизни больного. Ранняя диагностика системного амилоидоза позволяет своевременно начать лечение и увеличивает шансы на успех.

Ключевые слова: амилоидоз, классификация амилоидоза, клинические проявления амилоидоза, диагностика амилоидоза, амилоидоз сердиа, амилочдоз почек, амилочдоз желудочно-кичечного тракта

\section{Введение}

Амилоидоз - полисистемное заболевание с множеством клинических проявлений, имитирующих иную патологию внутренних органов, что приводит к поздней постановке правильного диагноза и несвоевременному началу лечения. В результате ухудшается прогноз и создается угроза жизни пациента. Ранняя диагностика данного заболевания позволяет своевременно заподозрить и в дальнейшем верифицировать амилоидоз, предотвратить вовлечение в процесс многих систем и органов. Ранняя постановка диагноза и инициация лече- ния улучшают прогноз заболевания и увеличивают шансы на успех. Системный амилоидоз представляет актуальную проблему современной медицины, что обусловлено трудностями диагностики, развитием серьезных осложнений и неблагоприятным исходом заболевания в отсутствие лечения. Частота выявления амилоидоза, по данным современных авторов, варьируется от 0,1 до 6,6\% [1]. Однако его распространенность в популяции может быть выше из-за недостаточной диагностики $[1,2]$. Трудности верификации диагноза обусловлены неспецифичностью жалоб на ранних стадиях заболевания [3], вовлечением в патологический процесс многих систем и органов, наличием клинических проявлений, характерных для ряда других заболеваний. Как следствие - позднее установление диагноза и несвоевременное начало лечения.

\section{Классификация и патогенез}

Амилоидоз представляет собой группу заболеваний, характеризующихся отложением во внеклеточном матриксе различных органов и тканей гликопротеида - амилоида, состоящего из нерастворимых фибриллярных протеиновых скоплений с широкой антипараллельной бета-складчатой структурой [4]. Полисахариды, входящие в состав амилоида, в основном представлены галактозой, глюкозой, реже галактозаминами, глюкозаминами, маннозой и фруктозой [1]. Белковые и углеводные фракции образуют между собой прочную связь, обеспечивающую устойчивость структуры амилоида к различному воздействию [1]. 10-15\% общей массы тканевого амилоида составляет фибриллярный белок P (Р-компонент), идентичный при всех вариантах амилоидоза. Его роль до конца не изучена $[1,5]$.

В настоящее время описано около 36 белков-предшественников, способных к формированию амилои- 
да при определенных условиях [6]. Свойства и биологические функции амилоидогенных белков различны. Это определяет патогенез заболевания и клинический вариант течения $[1,2,7]$, что лежит в основе современной классификации амилоидоза (таблица) [1, 8-10].

Наиболее распространенными вариантами на территории РФ являются AL-, AA-, ATTR- и Aß2M (диализный) амилоидоз [1, 10].

В настоящее время практикующие врачи также широко используют классификацию амилоидоза по этиологическому фактору, согласно которой амилоидоз подразделяется на идиопатический (первичный), наследственный (генетический), приобретенный (вторичный, реактивный), старческий и локальный $[1,9]$.

Каждому варианту амилоидоза присущ собственный патогенетический механизм развития, обусловленный особенностями белка - предшественника амилоида $[1,2]$.

При развитии AL-амилоидоза (A - amyloid, L - light chains of immunoglobulins) основным белком-предшественником для формирования фибрилл амилоида являются моноклональные легкие цепи лямбда- и каппа-типов иммуноглобулинов. В эту группу входят первичный (идиопатический) амилоидоз, амилоидоз при миеломной болезни, плазмоцитоме, В-клеточных опухолях, болезни тяжелых цепей, злокачественной лимфоме, болезни Вальденстрема, а также некоторые локальные формы амилоидоза $[1,11]$. В основе патогенеза AL-амилоидоза лежит плазмоклеточная дискразия, сопровождаемая интенсификацией продукции легких цепей иммуноглобулинов плазматическими или миеломными клетками [1]. Из легких цепей иммуноглобулинов на поверхности макрофагов (амилоидобластов), плотно контактирующих с плазматическими или миеломными клетками, осуществляется синтез амилоидных фибрилл [1]. AL-амилоидоз имеет наиболее распространенную и тяжелую форму. Для него характерно генерализованное течение с вовлечением в па- тологический процесс различных систем и органов $[1-3,9]$.

Системный АА-амилоидоз - вторичное заболевание [1], которое может развиваться на фоне любого хронического гнойного процесса, инфекционного, инфекционно-аллергического или опухолевого заболевания [1]. К наиболее частой предрасполагающей патологии относятся хронические гнойные болезни (остеомиелит, бронхоэктатическая болезнь, затяжное течение эндокардита), хронические воспалительные заболевания суставов (ревматоидный артрит, анкилозирующий спондилоартрит, псориатический артрит), воспалительные заболевания кишечника (неспецифический язвенный колит, болезнь Крона, болезнь Уиппла), туберкулез, сифилис, лимфогранулематоз, медуллярный рак щитовидной железы, опухоли паренхимы почки и легкого, наследственная патология (периодическая болезнь, синдром Макла - Уэллса (нефропатический семейный амилоидоз с глухотой, лихорадкой, крапивницей)) $[1,9]$.

\section{Современная классификация амилоидоза (Всемирная организация здравоохранения)}

\begin{tabular}{|c|c|c|}
\hline $\begin{array}{l}\text { Белок } \\
\text { амилоида }\end{array}$ & $\begin{array}{l}\text { Белок- } \\
\text { предшественник }\end{array}$ & Клиническая форма амилоидоза \\
\hline AA & SAА-белок & $\begin{array}{l}\text { Вторичный амилоидоз при хронических воспалительных } \\
\text { заболеваниях, в том числе периодической болезни и синдроме } \\
\text { Макла - Уэллса }\end{array}$ \\
\hline $\mathrm{AL}$ & $\begin{array}{l}\lambda \text {-, к- легкие цепи } \\
\text { иммуноглобулинов }\end{array}$ & $\begin{array}{l}\text { Амилоидоз при плазмоклеточных дискразиях - } \\
\text { идиопатический, при миеломной болезни } \\
\text { и макроглобулинемии Вальденстрема }\end{array}$ \\
\hline ATTR & Транстиретин & $\begin{array}{l}\text { Семейные формы полинейропатического, кардиопатического } \\
\text { и другого амилоидоза, системный старческий амилоидоз }\end{array}$ \\
\hline $\mathrm{A} \beta 2 \mathrm{M}$ & $\beta 2$-микроглобулин & Диализный амилоидоз \\
\hline AGel & Гелсолин & Финская семейная амилоидная полинейропатия \\
\hline AApoAI & $\begin{array}{l}\text { Аполипопротеин } \\
\text { А-I }\end{array}$ & Амилоидная полинейропатия (3-й тип по van Allen, 1956 г.) \\
\hline AFib & Фибриноген & Амилоидная нефропатия \\
\hline $\mathrm{A} \beta$ & $\beta$-белок & $\begin{array}{l}\text { Болезнь Альцгеймера, синдром Дауна, наследственные } \\
\text { кровоизлияния в мозг с амилоидозом, Голландия }\end{array}$ \\
\hline APrPScr & Прионовый белок & $\begin{array}{l}\text { Болезнь Крейтцфельдта - Якоба, болезнь Герстманна - } \\
\text { Штраусслера - Шейнкера }\end{array}$ \\
\hline AANF & $\begin{array}{l}\text { Предсердный } \\
\text { натрийуретический } \\
\text { фактор }\end{array}$ & Изолированный амилоидоз предсердий \\
\hline AIAPP & Амилин & $\begin{array}{l}\text { Изолированный амилоидоз в островках Лангерганса } \\
\text { при сахарном диабете 2-го типа, инсулиноме }\end{array}$ \\
\hline ACal & Прокальцитонин & При медуллярном раке щитовидной железы \\
\hline ACys & Цистатин C & Наследственные кровоизлияния в мозг с амилоидозом, Исландия \\
\hline
\end{tabular}

При АА-амилоидозе предшественником фибрилл амилоида является белок SAA, который в значительных количествах синтезируется в печени под влиянием провоспалительных цитокинов интерлейкинов 1 и 6, фактора некроза опухоли в ответ на воспаление или опухолевый рост $[1,2]$. Повышение уровня SAA в крови играет определяющую роль в патогенезе АА-амилоидоза [2]. При усилении продукции SAA и увеличении его содержания в крови интенсифицируется внутриклеточная деградация данного белка; из его фрагментов на поверхности макрофагов собираются фибриллы амилоида [2] с участием амилоид-стимулирующего фактора, который вырабатывается клетками различных тканей, преимущественно селезенки и печени [1]. При АА-амилоидозе наблюдается преимущественное поражение паренхиматозных органов - селезенки, почек, надпочечников и печени, в связи с чем выделяют нефропатический, эпинефропатический, гепатопатический и смешанный типы амилоидоза. Чаще развивает- 
ся нефропатический вариант - 90\% случаев АА-амилоидоза [1]. Семейный (наследственный) амилоидоз входит в группу заболеваний, наследуемых по аутосомнодоминантному типу и связанных с развитием мутантных белковых форм амилоидных фибрилл [1]. Выделяют ATTR (транстиретиновый) амилоидоз, амилоидоз, обусловленный развитием мутации аполипопротеина А-1, гелсолина, фибриногена А, лизоцима [1]. К наиболее распространенным вариантам этой группы относится ATTR (транстиретиновый) амилоидоз, который включает семейную амилоидную полиневропатию, кардиомиопатический вариант, а также системный старческий амилоидоз [1]. Развитие ATTR-амилоидоза обусловлено наличием мутаций, кодирующих структуру белка предшественника амилоида - транстиретина (ATTR), компонента фракции преальбумина, синтезируемого печенью и выполняющего функции транспортного белка тироксина и ретинола $[1,2]$.

Транстиретин представляет собой тетрамерный белок с четырьмя идентичными субъединицами. В результате мутации может происходить более 50 различных точечных замен аминокислот в структуре транстиретина [1], что приводит к формированию внутренне нестабильных вариантов мономеров и, как следствие, преципитации белка и его дальнейшей полимеризации в амилоидные фибриллы.

В настоящее время известно свыше 120 мутаций в гене транстиретина, большая часть из которых является амилоидогенной [12].

Особенности распределения амилоида в органах и тканях связывают с типом амилоидогенной мутации [7]. У 1/3 больных ATTR-амилоидозом в клинической картине превалируют признаки поражения периферической нервной системы, что свидетельствует о развитии семейной амилоидной (транстиретиновой) полиневропатии. У 1/3 пациентов доминируют кардиологические проявления, что говорит о формировании семейной амилоидной (транстиретиновой) кардиомиопатии. В остальных случаях формируется смешанный клинический вариант [12].

При ATTR-амилоидозе наряду c прогрессирующей периферической и вегетативной невропатией, поражением сердца и их сочетанием в патологический процесс могут вовлекаться другие системы и органы $[13,14]$. Кроме того, отложения транстиретина «дикого» типа (ATTR(wt)) являются причиной старческого системного амилоидоза, поражающего людей старше 60 лет [15].

\section{Клинические проявления}

Несмотря на различие в механизмах формирования типов амилоидоза, клинические проявления могут быть как сходными в силу идентичной локализации отложения амилоида, так и различными в отношении течения заболевания. Это позволяет предположить тот или иной вариант патологии [1].

При первичном амилоидозе средний возраст пациентов на момент постановки диагноза составляет около 55-65 лет [3], в то время как для вторичного амилоидоза характерно более раннее начало - 40-65 лет [2]. Развитие старческого амилоидоза возможно у больных старше 70 лет [2]. К наиболее ранним жалобам, предъявляемым пациентами с системным амилоидозом, относятся общая слабость, утомляемость, снижение работоспособности и массы тела (> 9 кг), парестезии, одышка.

Поражение сердца при AL-амилоидозе выявляется в 71-100\% случаев $[3,16]$, реже у пациентов c ATTR-амилоидозом. В то же время для АА-варианта этот симптом не характерен [2].

Ведущие клинические проявления, характеризующие вовлечение в патологический процесс сердечнососудистой системы, - одышка, ортостатическая гипотензия, отеки, обусловленные как сердечной недостаточностью, так и нефротическим синдромом.

Отложение амилоида в сердечной мышце может также вызывать нарушения проводимости, желудочковые или наджелудочковые аритмии, что обусловливает развитие у пациентов синкопальных состо- яний, появление жалоб на сердцебиение, перебои в работе сердца, головокружение.

Наличие амилоидоза сердца служит важным прогностическим критерием заболевания, поскольку 75\% летальных исходов связаны с прогрессированием сердечной недостаточности или нарушением ритма сердца [17]. В ряде случаев при поражении коронарных артерий заболевание манифестирует проявлениями ишемической болезни сердца или клинической картиной острого инфаркта миокарда [2, 17].

Поражение почек имеет место в 90\% случаев при АА-амилоидозе [1] и в 58-80\% случаев при $\mathrm{AL}-$-амилоидозе $[2,16]$. Значительно реже в патологический процесс при ATTR-амилоидозе вовлекается мочевыделительная система [2]. Клинические проявления амилоидной нефропатии, как правило, неспецифичны [1], начинаются с изолированной протеинурии с дальнейшим прогрессирующим течением и последовательной сменой стадий: протеинурической, нефротической, хронической почечной недостаточности $[2,10,11]$. У больного наблюдаются формирование отечного синдрома вплоть до развития анасарки, пенящаяся моча или симптомы уремии [16]. При амилоидозе почек редко отмечаются гематурия и лейкоцитурия, а также артериальная гипертензия $[1,3]$. В отдельных случаях амилоидная нефропатия манифестирует острым нефритическим синдромом и макрогематурией. В литературе встречаются данные о развитии синдрома Фанкони и тромбоза почечных вен при амилоидозе почек [2].

При системном амилоидозе может иметь место поражение периферической нервной системы, что в большей степени наблюдается при ATTR-, аполипопротеиновом A1 (AApoA1), гелсолиновом (AGel) амилоидозах и носит полиморфный характер. Прогрессирующая аксональная дегенерация развивается вследствие ишемии и компрессии нервных волокон, что обусловлено кумуляцией амилоида в эпиневрии, периневрии, эндоневрии, мелких кровеносных сосудах (vasa 
nervorum) и капиллярах [7]. Патологический белок также присутствует в связочном аппарате, вызывая сдавление нервов (клинически проявляется туннельными невропатиями), а также в интрамуральных сплетениях, блуждающем нерве и автономных ганглиях, обусловливая вегетативные нарушения [7].

При AL-амилоидозе клинические проявления со стороны периферической нервной системы развиваются в 17-35\% случаев и представлены в основном формированием сенсорно-моторной аксональной полинейропатии $[10,16,18]$. Полинейропатия проявляется нарушением болевой и температурной чувствительности в дистальных отделах нижних конечностей, что связано с поражением тонких нервных волокон и сопровождается парестезиями и дизестезиями [19]. При дальнейшем прогрессировании заболевания в патологический процесс вовлекаются хорошо миелинизированные крупные нервные волокна. В результате нарушается глубокая чувствительность и формируются вялые дистальные парезы [18, 19]. У 25\% пациентов с AL-амилоидозом выявляют двусторонний карпальный туннельный синдром (КТС) [10, 19], клинические проявления которого включают боль, чувствительные и двигательные нарушения в зоне иннервации срединного нерва [7].

У 65\% пациентов с AL-амилоидозом также имеют место симптомы поражения вегетативной нервной системы: тошнота, рвота, чередование диареи и запора, тазовые дисфункции, ортостатическая гипотензия и эректильные нарушения $[1,18]$. Наиболее частым проявлением автономной невропатии считается ортостатическая гипотензия. В отдельных случаях развивается миопатия, которая ассоциируется c AL-амилоидозом и для которой характерна слабость проксимальных групп мышц ног при изменении положения тела и подъеме по лестнице [7]. Не исключено формирование псевдогипертрофии скелетных мышц [20], связанное с кумуляцией амилоида в мышцах туловища. При AL-амилоидозе также может наблюдаться слабость мышц - сгибателей шеи, плечевого пояса и миалгии. В отдельных случаях миопатический синдром выявляют в дебюте амилоидоза до появления первых клинических симптомов поражения других систем и органов, что существенно затрудняет диагностику заболевания [20]. При AL-амилоидозе нередко поражается мускулатура верхних отделов дыхательных путей и глотки, вследствие чего развиваются клинические симптомы, такие как дисфагия и дисфония [21].

При ATTR-амилоидозе первые клинические симптомы поражения нервной системы связаны с онемением, покалыванием, жжением в стопах. Симптомы усиливаются в вечернее время и нередко сопровождаются болевым синдромом $[13,22]$. Подобные изменения обусловлены поражением тонких нервных волокон, участвующих в проведении болевой и температурной чувствительности. Впоследствии в патологический процесс вовлекаются более крупные, хорошо миелинизированные нервные стволы. Это приводит к нарушению глубокой чувствительности и развитию мышечной слабости, наиболее выраженной в дистальных отделах с постепенным распространением на проксимальные отделы конечностей. У пациентов с таким вариантом амилоидоза иногда нарушается походка из-за пареза мышц - разгибателей стоп, отмечаются гипо- и атрофия межкостных мышц кистей, тенара и гипотенара, деформация суставов, трофические язвы, цианотичность и снижение температуры кожных покровов кистей и стоп [18]. Наряду с явлениями полинейропатии и миопатии при ATTR-амилоидозе часто имеют место нарушения со стороны вегетативной нервной системы - ортостатическая гипотензия, диарея, рвота, гипо-/ангидроз, тазовые нарушения, эректильная дисфункция, которыми в ряде случаев манифестирует заболевание [18]. КТС при АТТР-амилоидозе наблюдается редко [18].

Поражения органов пищеварительного тракта при системном амилоидозе регистрируются в 70\% случаев $[2,10,16]$. Основными клиническими симптомами, свидетельствующими о вовлечении в патологический процесс желудочно-кишечного тракта (ЖКТ), являются снижение веса, диарея, тошнота, рвота съеденной пищей, боль в области живота, синдром мальабсорбции, изжога, дисфагия [23-26]. 25\% пациентов с AL-амилоидозом часто жалуются на диарею. Основной причиной диареи при AL-амилоидозе является автономная (вегетативная) дисфункция с поражением нервных сплетений кишечника [2]. Диарея вследствие инфильтрации кишечной стенки амилоидом возникает редко. Дифференциальная диагностика между диарейным синдромом на фоне отложения амилоида в стенке ЖКТ и моторной диареей вследствие поражения вегетативной нервной системы затруднительна. Нарушение всасывания при амилоидозе, как правило, носит вторичный характер, истинный синдром мальабсорбции развивается лишь в 4-5\% случаев $[2,9]$. При АА-амилоидозе в патологический процесс вовлекаются также органы ЖКТ. Диарея и синдром мальабсорбции могут быть единственными клиническими проявлениями при этом варианте амилоидоза.

У 25\% больных первичным амилоидозом наблюдается амилоидное поражение пищевода, чем объясняются жалобы пациентов на дисфагию и/или изжогу $[2,10]$. Поражение желудка, двенадцатиперстной кишки и кишечника может носить бессимптомный характер или сопровождаться развитием серьезных осложнений - изъязвлениями и перфорацией их стенок с возможным кровотечением, а также препилорической обструкцией желудка или механической кишечной непроходимостью из-за отложения амилоидных масс $[2,3]$. Редкий симптом, регистрируемый при вовлечении в патологический процесс органов ЖКТ, - гастропарез. Частота его выявления при амилоидном поражении желудка составляет 5\% [27]. У больных с преимущественным поражением толстой кишки возможно появление клинических симптомов, имитирующих язвенный колит [2]. 
Как известно, локализация разных типов амилоида ассоциирована с конкретными отделами ЖКТ. Так, AL-каппа- и AA-амилоидоз чаще выявляются в верхних отделах пищеварительного тракта, ATTR- и AL-лямбда-амилоидоз в нижних отделах ЖКТ - толстой кишке $[28,29]$. Этим объясняются особенности клинической картины. Одним из самых распространенных органов, вовлекаемых в патологический процесс при системном амилоидозе, является печень. Так, при AL- и AA-амилоидозе поражение печени регистрируется практически в $100 \%$ случаев $[2,10]$, в то время как при наследственных формах - лишь в 50\% случаев [1]. При этом наблюдается увеличение органа в размерах в сочетании с 1,5-4-кратным повышением активности гамма-глутамилтранспептидазы и щелочной фосфатазы без признаков печеночно-клеточной недостаточности $[3,10]$. Тяжелое поражение печени с выраженной гепатомегалией, развернутыми признаками тяжелого холестатического гепатита и печеночно-клеточной недостаточностью встречается редко [2]. Амилоидоз печени может клинически проявляться развитием боли, дискомфорта, тяжести в правом подреберье, метеоризмом, тошнотой, в редких случаях - желтухой и другими симптомами, сопровождающими гепатопатию любой этиологии [1]. При системном амилоидозе и гепатомегалии необходимо проведение дифференциальной диагностики между пассивным застоем крови в печени на фоне сердечной недостаточности и инфильтрацией печени амилоидом.

Поражение селезенки при системном амилоидозе включает в себя спленомегалию, которая встречается нечасто (в 5\% случаев), и селезеночную дисфункцию (гипоспленизм), которую выявляют на основании данных клинического анализа крови у больных амилоидозом в $24 \%$ случаев [1, 3, 10]. Редким проявлением амилоидоза селезенки считается ее спонтанный разрыв [3, 10].

Увеличение в объеме и уплотнение языка (макроглоссия) вследствие отложения амилоида может развиваться в 15-29\% случаев [2, 3], является патогномоничным признаком AL-амилоидоза и совместно с поднижнечелюстной припухлостью может быть причиной ночной асфиксии и нарушения речи $[1,3,10$, 16]. Нарушение вкуса также свойственно больным амилоидозом, даже в отсутствие макроглоссии [1]. Развитие дисфонии и дисфагии нередко связывают с инфильтрацией голосовых связок амилоидом $[1,21]$.

Частота поражения легких при амилоидозе варьируется от 31 до $88 \%$ [30]. При этом значительное количество пульмонологических расстройств выявляется у больных $\mathrm{AL}-\mathrm{aмилоидозом} \mathrm{и} \mathrm{диагностиру-}$ ется в 63-80\% случаев [30], в то время как у пациентов с АА-амилоидозом - лишь в 10-14\% случаев [2]. Вовлечение в патологический процесс легких характеризуется развитием наиболее часто встречающихся трех клинических форм: диффузной альвеолярносептальной (односторонний или двусторонний паренхиматозный амилоидоз), узловой и трахеобронхиальной [30]. Значительно реже выявляют амилоидную внутригрудную лимфаденопатию и амилоидную инфильтрацию диафрагмы [30]. Зачастую поражение легких при амилоидозе протекает бессимптомно или с несущественной клинической симптоматикой $[1,3]$. При наличии у пациента одышки необходимо проводить дифференциальную диагностику между застойной сердечной недостаточностью и распространенным легочным амилоидозом [1]. Рецидивирующий гидроторакс при системном амилоидозе, как правило, следствие застойной сердечной недостаточности на фоне сопутствующей амилоидной кардиомиопатии или нефротического синдрома при амилоидной нефропатии [30]. Однако в ряде случаев обширный плевральный амилоидоз имеет самостоятельное значение $[1,10]$ и сопровождается развитием хилоторакса [30].

Значительное снижение массы тела (9-18 кг) может иметь место у больных системным амилоидо- зом вследствие нарушения питания и кровоснабжения мышц на фоне периферической амилоидной полиневропатии, а также в результате моторной диареи [9].

Поражение кожи при первичном амилоидозе выявляется в 10-40\% случаев [2]: помимо патогномоничной для AL-амилоидоза периорбитальной гематомы, возникающей после легкой травмы или физической активности [16], могут появиться различные геморрагические высыпания иной локализации, папулы, узелки, бляшки, пятна, пузырьковые высыпания, преимущественно на лице и туловище [2, 3]. Достаточно распространены петехии век, но их легко упустить, если глаза пациента не закрыты. Зачастую выявляется индурация кожи по типу склеродермической. К редким проявлениям поражения кожи при первичном амилоидозе относятся нарушения пигментации (от потемнения кожных покровов до тотального альбинизма), алопеция и трофические нарушения [2]. При AL-амилоидозе могут наблюдаться потенциально опасные геморрагические осложнения из-за отложения амилоида в сосудистой стенке в сочетании с дефицитом или без дефицита факторов свертывания (в основном ингибитора тромбина, X фактора, реже V или IX) $[16,31,32]$, что обусловлено связыванием кальций-зависимых факторов свертывающей системы крови с амилоидом [1].

Поражение опорно-двигательного аппарата при первичном амилоидозе встречается в 5-10\% случаев и может включать прогрессирующую двустороннюю симметричную полиартропатию с вовлечением межфаланговых суставов кисти, лучезапястных, локтевых и плечевых суставов [3, 33]. Кроме того, амилоид способен накапливаться в сухожилиях, приводя к развитию сгибательных контрактур [3].

Поражение экзокринных желез также может наблюдаться при системном амилоидозе [1-3]. Так, у пациентов с артериальной гипотензией и гипонатриемией необходимо проводить дифференциальную диагностику между гипофункцией надпочечников 
в результате инфильтрации коры надпочечников амилоидом, вегетативной дисфункцией и сердечной недостаточностью [1]. У пациентов с первичным амилоидозом в патологический процесс вовлекается щитовидная железа, что приводит к развитию гипотиреоза в 10-20\% случаев [1]. Имеются данные о развитии синдрома Шегрена на фоне AL-амилоидоза [3].

\section{Диагностика}

При подозрении на системный амилоидоз применяют комплексный подход к диагностике данного заболевания. Проводят детальный опрос пациента с уточнением жалоб, анамнеза жизни (включая семейный анамнез) и заболевания, выполняют тщательное объективное обследование. С учетом вовлечения в патологический процесс многих систем и органов необходимо привлекать врачей смежных специальностей (нефрологов, кардиологов, эндокринологов, гастроэнтерологов и др.). Диагностика амилоидоза основана на сочетании клинических данных и результатов лабораторно-инструментальных обследований, среди которых основополагающая роль принадлежит морфологическому исследованию биоптатов пораженных органов и тканей [1].

Обычно в целях диагностики амилоидоза выполняют биопсию слизистой оболочки прямой кишки, почки, печени, подкожно-жировой клетчатки $[5,8]$. При AL-амилоидозе биопсия слизистого и подслизистого слоев прямой кишки позволяет выявить амилоид у 70\% больных. Чувствительность биопсии слюнной железы составляет около 90\% [16]. Аспирационная биопсия подкожной жировой клетчатки считается простой процедурой с высоким профилем безопасности, информативность которой при AL-амилоидозе достигает $80 \%$ [1,33]. К преимуществу данной процедуры относится также низкая частота развития кровотечений, что позволяет использовать данный метод у пациентов с геморрагическим синдромом и нарушением свертывания крови [33]. При наличии синдрома запястного канала проводится исследование ткани, удаленной при декомпрессионной операции. При подозрении на развитие AL-амилоидоза выполняется пункция костного мозга с подсчетом плазматических клеток. Это помогает не только диагностировать данный вариант амилоидоза, но и осуществлять дифференциальную диагностику между идиопатическим типом и AL-амилоидозом, ассоциированным с миеломной болезнью $[1,33]$.

Диагностика амилоидоза основана на выявлении при морфологическом исследовании конго-ротпозитивных внеклеточных масс амилоида, которые при микроскопии в поляризованном свете дают двойное лучепреломление, что обусловливает появление яблочно-зеленого окрашивания $[1,3,33]$. Для определения типа амилоидоза применяется проба с перманганатом калия. При обработке 5\%-ным раствором перманганата калия препаратов с АА-типом амилоида, предварительно окрашенных конго красным, утрачивается свойство двойного лучепреломления, чем объясняется исчезновение яблочно-зеленого цвета. В то же время при AL-типе амилоида это свойство сохраняется [33]. Использование щелочного гуанидина позволяет более точно дифференцировать варианты AA- и AL-амилоидоза [33].

Современная морфологическая диагностика амилоидоза также предполагает проведение иммуногистохимического типирования амилоида для определения дальнейшей тактики лечения [24, 29, 34]. Наиболее точным считается иммуногистохимическое типирование с использованием моноклональных антител к белкам - предшественникам амилоида - специфических антител против АА-белка, легких цепей иммуноглобулинов (лямбда, каппа), транстиретина и бета-2-микроглобулина [25, 35]. Однако его результаты не всегда достоверны (не более чем в 50\% случаев) из-за присутствия нормальных иммуноглобулинов, а также возможности потери амилоидных цепей при фиксации материала. Электронная микроскопия совместно с массспектрометрией позволяет верифицировать все известные типы амилоида, поэтому данный метод считается наиболее достоверным. Лазерная диссекция и масс-спектрометрия на основе протеомного анализа признаны золотым стандартом для типирования амилоида со специфичностью $100 \%$ и чувствительностью 90\% [16].

При подозрении на системный амилоидоз проводится оценка парапротеинов [8, 10, 36]. Широко применяемые в рутинной практике методы простого белкового электрофореза и иммуноэлектрофореза зачастую недостаточно эффективны в выявлении моноклональной гаммапатии при AL-амилоидозе [36]. В связи с этим в настоящее время применяется иммунофиксирующий электрофорез сыворотки крови или мочи, что позволяет в большинстве случаев обнаружить повышенное содержание каппа- и лямбда- легких цепей $[1,36,37]$. Дополнительно используется метод количественного определения свободных легких цепей иммуноглобулинов в крови - Freelite-test [36, 38]. С помощью этого теста определяются циркулирующие в крови амилоидогенные фибриллы белка-предшественника с чувствительностью 85-98\% [38]. Рекомендовано одновременное применение метода электрофореза, метода иммунофиксации крови и суточной мочи, а также количественной оценки уровня свободных легких цепей иммуноглобулинов в сыворотке крови методом Freelite $[10,13]$.

В клиническом анализе крови при системном амилоидозе могут наблюдаться явления гипоспленизма (за счет массивного отложения амилоида в селезенке), о чем свидетельствует развитие тромбоцитоза в сочетании с появлением телец Жолли в эритроцитах [10].

По данным общего анализа мочи, при поражении почек на фоне амилоидоза определяется протеинурия, преимущественно за счет альбуминурии. При AL-амилоидозе в 20-45\% случаев наблюдается снижение скорости клубочко- 
вой фильтрации. При амилоидозе почек массивная протеинурия с генерализованными отеками и гипоальбуминемией может развиваться в том числе при нормальном уровне креатинина и мочевины крови [2].

Для определения наследственных форм амилоидоза и проведения дифференциальной диагностики между наследственными вариантами и AL-типом амилоидоза применяют генетическое тестирование с целью выявления мутаций в генах транстиретина, аполипопротеина, гелсолина $[1,8,13,14]$.

Для верификации нарушений со стороны сердца при амилоидозе используют электро- и эхокардиографию, холтеровское мониторирование, магнитно-резонансную томографию, сцинтиграфию с пирофосфатом технеция [5, 8, 39]. Согласно последним данным, амилоидоз сердца считается подтвержденным в случае выявления амилоидной инфильтрации сердца (по данным эндомиокардиальной биопсии) или утолщения стенки левого желудочка (ЛЖ) более 12 мм (по данным ЭхоКГ) в отсутствие артериальной гипертонии или других причин гипертрофии ЛЖ и положительной окраски на амилоид некардиальных тканей (по данным гистологического исследования) [40]. Характерными признаками амилоидоза сердца, по данным ЭКГ, являются: низкий вольтаж QRS и/или комплексы QS, недостаточное нарастание зубцов R; типичен диффузный характер изменений (сглаженность или инверсия зубца Т во многих отведениях), наличие аритмии и нарушения проводимости, псевдоинфарктные изменения $[5,8$, 39]. При проведении МРТ сердца у пациентов с амилоидозом регистрируют субэндокардиальное накопление гадолиния, которое имеет высокую чувствительность и специфичность, в частности при $\mathrm{AL}-$ амилоидозе [5]. По данным ЭхоКГ, при амилоидозе наблюдаются выраженное утолщение стенок недилатированного ЛЖ, признаки рестриктивного наполнения, расширения обоих предсердий, утолщение клапанов, на- личие перикардиального выпота [41]. Сочетание нескольких перечисленных признаков существенно повышает вероятность наличия амилоидоза сердца [8]. Для диагностики амилоидоза сердца также применяют сцинтиграфию с изотопом технеция 99mТc-пирофосфатом, которая выявляет значительное накопление радиоизотопа миокардом при наличии транстиретинового амилоида и является надежным неинвазивным методом верификации ATTR-типа амилоидоза [14, 42, 43]. Сцинтиграфия миокарда с изотопом технеция 99mTc-DPD (дикарбоксипропандифосфонат) может применяться в целях дифференциальной диагностики между старческим и ALтипом амилоидоза, при котором накопление препарата в миокарде несущественно [44].

По данным УЗИ органов брюшной полости, при системном амилоидозе могут выявляться гепатомегалия, спленомегалия и нефромегалия, что свидетельствует о вовлечении в патологический процесс данных органов вследствие накопления амилоида.

Наряду с применением УЗИ для диагностики амилоидоза печени в настоящее время используют эластографию (фиброскан) [45]. В некоторых странах мира доступна сцинтиграфия печени с йод123-меченным сывороточным амилоидом Р (123I-SAP) [3].

При эндоскопическом обследовании ЖКТ при подозрении на амилоидоз можно обнаружить расширенный пищевод, признаки снижения перистальтики органов ЖКТ [16], эрозии, изъязвления, интрамуральные гематомы, субмукозные опухолеподобные массы, утолщение слизистой оболочки желудка $[46,47]$ и других отделов ЖКТ.

Для выявления поражения периферической нервной системы при амилоидозе применяют стимуляционную и игольчатую электромиографию (ЭМГ), вызванные кожные симпатические потенциалы (ВКСП), количественное сенсорное тестирование (КСТ) [7]. Стимуляционная ЭМГ позволяет определить аксонопатию по уров- ню снижения амплитуды моторных и сенсорных ответов, поражение миелиновой оболочки, проявляющееся снижением распространения возбуждения по нервам, а также их сочетание. Вследствие поражения тонких нервных волокон на ранних стадиях заболевания стимуляционная ЭМГ может быть недостаточно информативна. Тогда проводится КСТ [48]. В случае, когда начало заболевания сопровождается вегетативными расстройствами, необходимо проведение ортостатической пробы, оценки вариабельности сердечного ритма и исследования ВКСП. С целью объективной оценки вовлечения в патологический процесс при амилоидозе скелетной мускулатуры используют игольчатую ЭМГ.

Диагноз системного амилоидоза следует заподозрить у любого больного:

$\checkmark$ с недиабетическим нефротическим синдромом;

$\checkmark$ неишемической кардиомиопатией с гипертрофией отделов сердца по данным эхокардиографии;

$\checkmark$ гепатомегалией или повышенным значением щелочной фосфатазы при исключении другой патологии;

$\checkmark$ хронической воспалительной демиелинизирующей полинейропатией с моноклональным белком;

$\checkmark$ при наличии моноклональной гаммапатии на фоне необъяснимой усталости, отека, потери веса или парестезий [4].

\section{Заключение}

Системный амилоидоз относится к трудно диагностируемой патологии, поскольку клинические симптомы зачастую имитируют признаки других наиболее распространенных заболеваний. Вовлечение в патологический процесс различных органов обусловливает многообразие жалоб пациента и клинических проявлений, что приводит к дифференциальным трудностям, поздней верификации диагноза, несвоевременному началу лечения и последующим осложнениям.

Авторы заявляют об отсутствии конфликта интересов. 


\section{Литература}

1. Шишкин А.Н. Амилоидные болезни // Медицина, ХХІ век. 2008. № 10. С. 44-51.

2. Рамеев В.В., Козловская Л.В. Амилоидоз: современные методы диагностики и лечения // Эффективная фармакотерапия. 2012. № 44. С. 6-15.

3. Диспор Э., Бриду Ф., Сирак К. и др. AL-амилоидоз // Нефрология. 2014. Т. 18. № 4. С. 36-50.

4. Morie A., Gertz M.A. Immunoglobulin light chain amyloidosis: 2018 update on diagnosis, prognosis, and treatment // Am. J. Hemotology. 2018. Vol. 93. № 9. P. 1169-1180.

5. Дворецький Л.И., Карпова О.Ю., Александрова Е.Н. и др. Амилоидоз сердца у пожилых // Архивъ внутренней медицины. 2015. № 6 (26). С. 28-36.

6. Benson M.D., Buxbaum J.N., Eisenberg D.S. et al. Amyloid nomenclature 2018: recommendations by the International Society of Amyloidosis (ISA) nomenclature committee // Amyloid. 2018. Vol. 25. № 4. P. 215-219.

7. Сафиулина Э.И., Зиноввева О.Е., Рамеев В.В. и др. Поражение периферической нервной системы при системном амилоидозе // Неврология, нейропсихиатрия, психосоматика. 2018. Т. 10. № 3. С. 12-18.

8. Комиссарова С.М., Богомазов А.И., Севрук Т.В. и др. Амилоидоз сердца в практике кардиолога // Кардиология в Беларуси. 2017. Т. 9. № 4. С. 648-661.

9. Нашатырева М.С., Зимина И.А., Горбачева М.В. и др. Первичный амилоидоз в практике врача-терапевта // Сибирский медицинский журнал. 2014. № 3. С. 104-107.

10. Козловская Л.В., Рамеев В.В. Клинические рекомендации по диагностике и лечению системного амилоидоза (AА, AL). Научное общество нефрологов России, 2014.

11. Радченко В.Г., Аниконова Л.И., Полякова В.В. Поражения почек при множественной миеломе и моноклональных гаммапатиях почечного значения // Профилактическая и клиническая медицина. 2014. № 4 (53). C. 97-106.

12. Sekijima Y. Transthyretin (ATTR) amyloidosis: clinical spectrum, molecular pathogenesis and disease-modifying treatments // J. Neurol. Neurosurg. Psychiatry. 2015. Vol. 86. № 9. P. 1036-1043.

13. Gudkova A.Ya., Amelin A.V., Krutikov A.N. Val30Met-транстиретиновая амилоидная полиневропатия и кардиомиопатия (обзор литературы и клиническое наблюдение) // Consilium Medicum. 2017. Т. 19. № 12. C. $109-116$.

14. Гудкова А.Я., Полякова А.А., Амелин А.В. Не VAL30MET-транстеритиновая амилоидная кардиомиопатия. Обзор сведений литературы и клиническое наблюдение // Российский кардиологический журнал. 2018. Т. 23. № 2. С. 121-128.

15. Полякова А.А., Семернин Е.Н., Ситникова М.Ю. Транстиретиновый амилоидоз в когорте пациентов с хронической сердечной недостаточностью старческого возраста и долгожителей // Кардиология. 2018. T. 58. № S2. C. 12-18.

16. Vaxman I., Gertz M. Recent advances in the diagnosis, risk stratification and management of systemic light-chain amyloidosis // Acta Haematol. 2019. Vol. 141. № 2. P. 93-106.

17. Kappor P., Thenappan T., Singh E. et al. Cardiac amyloidosis: a practical approach to diagnosis and management // Am. J. Med. 2011. Vol. 124. № 11. P. 1006-1015.

18. Shin S.C., Robinson-Papp J. Amyloid neuropathies // Mt Sinai J. Med. 2012. Vol. 79. № 6. P. 733-748.

19. Pearson K.T., Vota S. Amyloidosis and its management: amyloid neuropathies // Curr. Probl. Cancer. 2016. Vol. 40. № 5-6. P. 198-208.

20. Manoli I., Kwan J.Y., Wang Q. et al. Chronic myopathy due to immunoglobulin light chain amyloidosis // Mol. Genet. Metab. 2013. Vol. 108. № 4. P. 249-254.

21. Muchtar E., Derudas D., Mauermann M. et al. Systemic immunoglobulin light chain amyloidosis-associated myopathy: presentation, diagnostic pitfalls, and outcome // Mayo Clin. Proc. 2016. Vol. 91. № 10. P. 1354-1361.

22. Ng Wing Tin S., Plante-Bordeneuve V., Salhi H. et al. Characterization of pain in familial amyloid polyneuropathy // J. Pain. 2015. Vol. 16. № 11. P. 1106-1114.

23. Syed U., Ching Companioni R.A., Alkhawam H. et al. Amyloidosis of the gastrointestinal tract and the liver: clinical context, diagnosis and management // Eur. J. Gastroenterol. Hepatol. 2016. Vol. 28. № 10. P. 1109-1121.

24. Said S.M., Grogg K.L., Smyrk T.C. Gastric amyloidosis: clinicopathological correlations in 79 cases from a single institution // Hum. Pathol. 2015. Vol. 46. № 4. P. 491-498.

25. Inayat F., Hurairah A. Duodenal amyloidosis masquerading as iron deficiency anemia // Cureus. 2016. Vol. 8. № 8. P. e725.

26. Park S.W., Jee S.R., Kim J.H. et al. Duodenal amyloidosis secondary to ulcerative colitis // Int. Res. 2018. Vol. 16 . № 1. P. 151-154.

27. Hoscheit M., Kamal A., Cline M. Gastroparesis in a patient with gastric AL amyloidosis // Case Rep. Gastroenterol. 2018. Vol. 12. № 2. P. 317-321.

28. Гиоева 3.В., Михалева Л.М. Клинико-морфологические особенности амилоидоза желудка и двенадцатиперстной кишки // Журнал анатомии и гистопатологии. 2019. Т. 8. № 1. С. 39-43.

29. Freudenthaler S., Hegenbart U., Schönland S. et al. Amyloid in biopsies of the gastrointestinal tract - a retrospective observational study on 542 patients // Virchows Arch. 2016. Vol. 468. № 5. P. 569-577. 
30. Третьяков А.Ю., Захарченко С.П., Третьякова В.А. Легочный амилоидоз // Пульмонология. 2018. Т. 28. № 1. С. $75-83$.

31. Sucker C., Hetzel G.R., Grabensee B. et al. Amyloidosis and bleeding: pathophysiology, diagnosis, and therapy // Am. J. Kidney Dis. 2006. Vol. 47. № 6. P. 947-955.

32. Bouma B., Maas C., Hazenberg B.P. et al. Increased plasminalpha2-antiplasmin levels indicate activation of the fibrinolytic system in systemic amyloidosis // J. Thromb. Haemost. 2005. Vol. 5. № 6. P. 1139-1142.

33. Рамеев В.В., Козловская Л.В., Саркисова И.А. Амилоидоз: вопросы диагностики и лечения // Клиницист. 2006. № 4. С. 35-42.

34. Гиоева 3.В., Михалева Л.М., Рёкен К. Иммуногистохимическое типирование гастроинтестинального амилоидоза с использованием расширенного набора антител, направленных против AL-kappa амилоидоза // Журнал научных статей Здоровье и образование в XXI веке. 2017. Т. 19. № 2. С. 84-89.

35. Marmol M., Bethencourt Mirabal A., Sanchez N. et al. Specific clinical and morphological characteristics of amyloidosis of the stomach and duodenum // Crit. Care Med. 2019.

36. Рамеев В.В., Козловская Л.В., Гудкова К.В. и др. Первичный AL-амилоидоз: новое в представлениях о патогенезе, диагностике и лечении // Врач. 2013. № 1. С. 58-61.

37. Gillmore J.D., Wechalekar A., Bird J. Guidelines on the diagnosis and investigation of AL amyloidosis // Br. J. Haematol. 2015. Vol. 168. № 2. P. 207-218.

38. Смирнова Е.А. Системный AL-амилоидоз: трудности диагноза (обзор литературы и собственные данные) // Российский медико-биологический вестник имени академика И.П. Павлова. 2016. Т. 24. № 3. С. 141-153.

39. Благова О.В., Недоступ А.В., Седов В.П. и др. Клинические маски амилоидоза с поражением сердца: особенности диагностики на современном этапе // Российский кардиологический журнал. 2017. № 2 (142). С. 68-79.

40. Gertz M.A., Comenzo R., Falk R.H. et al. Definition of organ involvement and treatment response in immunoglobulin light chain amyloidosis (AL): a consensus opinion from the 10th International Symposium on Amyloid and Amyloidosis // Am. J. Hematol. 2005. Vol. 79. № 4. P. 319-328.

41. Eriksson P., Backman C., Eriksson A. et al. Differentiation of cardiac amyloidosis and hypertrophic cardiomyopathy. A comparison of familial amyloidosis with polyneuropathy and hypertrophic cardiomyopathy by electrocardiography and echocardiography // Acta Med. Scand. 1987. Vol. 221. № 1. P. 39-46.

42. Perugini E., Guidalotti P.L., Salvi F. et al. Noninvasive etiologic diagnosis of cardiac amyloidosis using 99mTc-3,3-diphosphono1,2-propanodicarboxylic acid scintigraphy // J. Am. Coll. Cardiol. 2005. Vol. 46. № 6. P. 1076-1084.

43. Rossi P., Tessonnier L., Frances Y. et al. 99mTc DPD is the preferential bone tracer for diagnosis of cardiac transthyretin amyloidosis // Clin. Nucl. Med. 2012. Vol. 37. № 8. P. e209-e210.

44. de Haro-del Moral FJ., Sánchez-Lajusticia A., Gómez-Bueno M. et al. Role of cardiacscintigraphy with 99mTc-DPD in the differentiation of cardiac amyloidosis subtype // Rev. Esp. Cardiol. (Engl. Ed.). 2012. Vol. 65. № 5. P. 440-446.

45. Loustaud-Ratti V.R., Cypierre A., Rousseau A. et al. Noninvasive detection of hepatic amyloidosis: FibroScan, a new tool // Amyloid. 2011. Vol. 18. № 1. P. 19-24.

46. Hashimoto R. Kappa light-chain amyloidosis of gastrointestinal tract // Ann. Gastroenterol. 2018. Vol. 32. № 1. P. 109.

47. Iida T., Yamano H., Nakase H. Systemic amyloidosis with gastrointestinal involvement: diagnosis from endoscopic and histological views // J. Gastroenterol. Hepatol. 2018. Vol. 33. № 3. P. 583-590.

48. Chao C.C., Huang C.M., Chiang H.H. et al. Sudomotor innervation in transthyretin amyloid neuropathy: pathology and functional correlates // Ann. Neurol. 2015. Vol. 78. № 2. P. 272-283.

\section{Systemic Amyloidosis: Clinical Manifestations and Diagnosis}

N.V. Bakulina, PhD, Prof. ${ }^{1}$, A.S. Nekrasova, $\mathrm{PhD}^{1}$, A.Ya. Gudkova, PhD, Prof. ${ }^{2}$, E.L. Latariya, PhD ${ }^{3}$, V.V. Gomonova ${ }^{3}$, D.B. Tsurtsumiya, $\mathrm{PhD}^{1}$

${ }^{1}$ I.I. Mechnikov North-Western State Medical University

${ }^{2}$ Academician I.P. Pavlov First St. Petersburg State Medical University

${ }^{3}$ Great Peter Hospital

Contact person: Natalya V. Bakulina, natalya.bakulina@szgmu.ru

This review is devoted to the current state of the problem of diagnosis of systemic amyloidosis at the outpatient stage and in a multidisciplinary hospital. The article summarizes the existing information about the variants of the clinical course and provides current methods of verification of this disease. In systemic amyloidosis, the involvement of different systems and organs in the pathological process, the variety of clinical manifestations and nonspecific complaints of the patient in the early stages of this disease often lead to untimely establishment of the correct diagnosis and late initiation of treatment, worsening the prognosis and posing a significant threat to the life of the patient. Early diagnosis of systemic amyloidosis allows the patient to start treatment on time and increases the chances of success.

Key words: amyloidosis, classification of amyloidosis, clinical manifestations of amyloidosis, diagnosis of amyloidosis, amyloidosis of the heart, amyloidosis of the kidneys, amyloidosis of the gastrointestinal tract 